\title{
Organizational Size: A Key Element In The Development Of Private Enterprises In The Less Developed Countries: The Case Of Ecuador
}

\author{
John Demetrios Theodore, Ph.D., D.B.A., CMC, Warner University, USA
}

\begin{abstract}
The purpose of this article was to examine and evaluate the prerequisites needed in private enterprises in Ecuador that are conducive to economic development and determine if economic development via this choice is feasible. The prerequisites are ample organizational size, a situation that allows the formation of a well-constructed and viable organizational structure with three hierarchal levels and sufficient departmentalization. All of the above permits the formation, sustenance, and development of the chain and unity of command; span of control; and delegation which, when integrated with the organizational structure, organizational levels, and departmentalization, form the infrastructure for organizational development. It was determined that most Ecuadorian enterprises do not posses such prerequisites; therefore, they cannot play the needed role for micro-economic development at this time.
\end{abstract}

Keywords: Organization development, microeconomic development, organization size, organizational structure, organizational levels, departmentalization, delegation, span of control, chain and line of command

\section{INTRODUCTION}

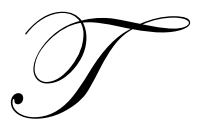

he production of petroleum, small scale manufacturing, fishing, and agriculture constitute the most important segments of the Ecuadorian economy. The economy is segmented into three components: the First Sector that includes agriculture, forestry, and fishing; the Second Sector entails manufacturing, mining, construction, raw materials, and handicrafts; and the Third Sector is comprised of commerce, tourism, finance, services, and transportation (Ospina Peralta, 2007). Ecuador's GDP product was $\$ 57.23$ billion in 2005, $\$ 60.48$ billion in 2006, and 98,79 billion in 2007 based on increases in petroleum exports (Vasquez \& Santos, 2008) However, the non-petroleum economic activities remained stagnant due to diseconomies of scale (Acosta, 2006). The overall economy started to rapidly decline at the end of 2007 due to the decline of petroleum exports and the decreased investment in the private sector. The latter occurred mainly due to the advent of the election of the socialist president, Rafael Correa in December, 2006. Despite the fact that Ecuador has large petroleum reserves, the country has not been able to take full advantage of such assets in order to develop its slowmoving economy. President Correa is favoring a socialist and macroeconomic model of economic development, whereas the private sector is supporting microeconomic development. Correa's economic plan of 2007-2010 proposes to achieve economic revitalization through social justice and freedom under the auspices of the government (Luna Osorio, 2007). Ecuador's private sector favors a free-market approach whose infrastructure is predicated on the productivity, performance, and competitiveness of the country's private enterprises. They claim that the economy based on the free market system will be conducive to the development of all economic factors, especially the human one, because it provides and sustains freedom (Lucio-Paredes, 2008).

This article evaluates the prerequisites needed in Ecuador's private enterprises that are conducive to drive economic development and determine if economic development via this choice is feasible at the present time. In order for private enterprises to reach a level of effective and efficient performance, they need to meet certain 
important prerequisites. According to the present author's Holistic Management model (Theodore, 2003), such prerequisites start with an ample organizational size, a situation that allows the formation of a well-constructed and viable organizational structure with three hierarchal levels, and sufficient departmentalization. All of the above permit the formation, sustenance, and development of the chain and unity of command; span of control; and delegation which, which when integrated with the organizational structure, organizational levels and departmentalization form the infrastructure for organizational development.

Organizational development is a planned change effort which involves all the parts of the organization (Schein 1988). It is initiated and managed from the top hierarchy of the system and it is designed to increase organizational effectiveness. The ultimate goal of organization development is to make the organization more open and more adaptive through increases in capability and potential in order for it to continue making such planned change efforts on an action orientation basis (Theodore, 2002).

\section{ORGANIZATIONAL SIZE}

Organizational size is the structural property of the organization and can be defined in terms of space volume, sales volume, net assets, customers, or the number of persons employed in the organization. In this study, organizational size denotes the number of employees and managers employed in organizations. The size of a firm affects its organizational structure which subsequently impacts the levels of the structure and its departmentalization. There is considerable evidence than an organization's size significantly affects its structure. Large organizations tend to have more specialization, departmentalization, centralization, and rules and regulations than do small organizations (Robins \& Coulter, 2005)

\section{ORGANIZATIONAL STRUCTURE}

Organizational structure is defined as a stable framework that depicts how the human and non-human elements in it are arranged and grouped. It is based on the organization's mission, goals, and objectives. The number, diversity, and complexity of an organization's goals should play an important role in decisions about how it should be structured or designed (Hodge, Anthony \& Gales, 2003). Non-human elements include positions, job duties, lines of authority, formal patterns of activities, and relationships that connect the various constituent parts of the structure, such as hierarchical levels, divisions, departments, etc. Within departments, the respective managers and employees (the human element) form the span of control, chain and unity of command, and delegation. Within the organizational structure, and specifically within its divisions and departments, activities are being performed on a continuous basis, most of the time. Non-routine activities also occur in some cases, as demanded by contingencies.

\section{ORGANIZATIONAL LEVELS}

If there is sufficient organizational size and an ample structure, three levels in the organizational hierarchy are formed: top, middle, and lower/operational. In the top level reside the executives whose function is to direct the strategic elements of the organization. This level is the leadership level because the executives are monitoring the external environment and move the organization toward any direction that environmental factors dictate. This results in the creation of commensurate strategies that serve as the forces that guide the organization toward the desired path. The middle level performs strategic functions, too, but such functions are for short-term purpose or tactical functions. Middle managers are expected to translate the delegated strategies from the leadership level into tactical actions that include specific goals and applications. While the ranks of middle managers have decreased during the last 30 years due to downsizing, leaning efforts and the increased reliance on project teams, middle managers continue to play an important role between the top and lower levels. Middle management controls and interprets the vertical communication process and the commensurate channels of communication.

A major part of the middle manager's job is developing and fine-tuning skills and know-how, such as manufacturing or marketing expertise that allow the organization to be efficient and effective (Jones \& Jones, 2007). Finally, the lower, or operational level, is a supervisory level for all practical purposes. They supervise their respective employees, and represent to the latter, the image of the entire organization. In addition, they implement the organization's operations through their assigned employees. 


\section{DEPARTMENTALIZATION}

A well constructed organizational structure, with its well-formed three hierarchal levels, creates the need for a viable departmentalization. Well defined departments are formed, maintained, and developed to implement a firm's strategic plan. Departmentalization denotes how job activities are clustered together. Of paramount importance is the rationale for the clustering or grouping of such activities. More specifically, the entirety of the tasks existing in the organizational structure is divided into smaller numbers, which are placed into respective departments with strong emphasis upon an effective and efficient coordination of activities. The execution of such activities needs to take place on a priority basis, under specific guidelines, and in a prescribed sequence. This activity chain produces work specialization that creates an effective and efficient departmental and organizational operation. Horizontal communication and communication channels are established among departments at each organizational level, whereas vertical communication and communication channels are created among departments and are found in each level. Centralization and decentralization of activities are also created within departments. One rationale in grouping tasks is based on the functions performed, such as production, marketing, human resources, finance, etc. Functional departmentalization is popular because it permits those with similar technical expertise to work in a coordinated subunit (Kreitner, 2001). Another rationale for multi-product organizations is to departmentalize according to products, such as formal footwear, casual footwear, etc. An additional rationale is to create departments based on customers, such as industrial customers, commercial customers, or consumer customers. For large organizations, geographic departmentalization is based on where the customers are located, such as in New England, California, Florida, etc. An advanced organizational structure, well-defined and operating top, middle, and lower organizational levels; and ample departmentalization that performs effectively and efficiently within the organizational confines result in the following three powerful principles of organization: Chain and Unity of Command; Span of Control; and Delegation.

\section{CHAIN AND UNITY OF COMMAND}

Chain of command is the uninterrupted line of authority that starts at the top organizational level and ends at the individual employee stratification below the operational level. It denotes whom each person is accountable to on a vertical basis, whereas unity of command indicates that each subordinate must report to only one superior in the chain of command. The principle of the chain of command includes the concept of authority, which means that a superior in the chain has power to control the direct subordinates. This situation creates accountability in the unity of command to ensure that subordinates are accountable to their superiors (Jones \& Jones, (2007). The bloodline of the chain and unity of command is upward and downward communication within the vertical channels of communication. Both the chain and unity of command create control, synergy, communication and communication channels, and a viable network in which the tasks of the organization are performed.

\section{SPAN OF CONTROL}

Span of Control has to do with the number of subordinates a superior controls on a vertical basis. The number of people under a manager is an important feature of an organization's structure. The number of subordinates who report directly to an executive or supervisor is called span of control (Bateman \& Snell, 2002). This creates an interpersonal relationship between the two hierarchal elements based on the number of subordinates and the interaction that takes place between them and the superior, thus precipitating the implementation of delegation. The span of control defines how many managers and how many levels of management exist in the organization. In this organizational principle, there is an additional need for employee and management skills and abilities so that both sides can interact effectively, efficiently, and fruitfully.

\section{DELEGATION}

Delegation is the process of passing authority and responsibility from higher to lower levels in the organizational hierarchy. Delegation is the assignment of authority and responsibility to a subordinate at a lower level. It is the most fundamental feature of management because it entails getting work done through others (Hellriegel, Jackson, \& Slocum, 2005). Adequate and sufficient delegation of authority and responsibility is conducive to the development of professional management because the recipients of the delegation have the 
opportunity to make their own decisions, thus developing their capabilities, expertise and skills that pave the way to their managerial development. Furthermore, effective and efficient delegation creates competition among the recipient managers who are induced through motivation to compete and excel in the various tasks they receive from higher levels. The recipients of delegation also acquire a degree of independence in doing certain delegated tasks. Such independence is another excellent motivator, especially in setting goals within their own sphere of operation within commensurate departments and the entire organization. Finally, before delegation of authority and responsibility takes place, the delegators need to determine if the recipients of delegation are competent and have the required motivational infrastructure to be used for additional motivational increases as the result of delegation.

\section{THE CASE OF ECUADOR}

The Ecuadorian economy is composed of a very large number of private organizations of small size. Small and medium-sized enterprises constitute $97 \%$ of all enterprises in the country (Vasquez \& Santos, 2008). This factor is a tremendous impediment toward the creation of a critical mass of appropriately sized organizations that can utilize the above-mentioned organizational structures. The small size and proliferation of family owned and managed enterprises (and consequently the traditional rigid structure) have impeded their economic development and modernization of management techniques. Ecuador's private sector is characterized by enterprises that typically employ small numbers of family members who function both as managers and employees (Hurtado, 2007). Consequently, the organizational structure remains rigid and underdeveloped, thus preventing the natural formation of organizational levels. In order for Ecuadorian business enterprises to survive and develop, their senior management and ownership must make substantial and fundamental changes not only to their business models but also their organizing principles. Laconically stated, Ecuador's business owners and managers need to redefine and implement the organization's strategy formulated in the upper organizational level and delegated to lower levels that do not currently exist ( Arosemena-Arosemena, 2008). The absence of the middle and lower/operational levels is evident in the majority of enterprises. Most of the business organizations have only the top managerial level that consists of the owners (Vasquez \& Santos, 2008). Departmentalization is non-existent in the majority of private organizations. Departments that do exist in some organizations are limited to a very small number of large enterprises. The remaining enterprises have no established departments (Luna Osorio, 2007). This reality has caught the attention of some researchers in Ecuador who claim that departments need to be formed in order to provide sufficient impetus for the development in Ecuadorian enterprises (Correa, 2008). Finally, the principle of delegation is highly retarded due to the Latin American social and business culture that favors centralization of control. In Ecuador, the ownership of business organizations, in most cases, has exhibited no desire to modernize and develop their organizations. Following the political philosophy of the country, all decisions are centralized, thus impeding delegation (Hurtado, 2007).

\section{CONCLUSIONS AND RECOMMENDATIONS}

It is evident that Ecuadorian private enterprises are not currently in a position to contribute toward economic development. The author proposes two immediate actions on the part of the ownership and management of such enterprises: (1) conduct mergers that will precipitate larger organizational size (Arosemena-Arosemena 2007) and (2) provide advanced education in the areas of management and organizational development for both managers and owners in order for them to be qualified and ready to implement the advanced managerial and organizational practices needed by the newly formed and emerged enterprises (Theodore, 1999).

\section{AUTHOR INFORMATION}

John Theodore is the holder of a Ph.D. degree in Administration and Latin American Studies from the University of Kansas; a Ph.D. in Management from the Aristotelian University in Greece, European Union; and a D.B.A. in International Business from the University of South Africa. He has been teaching and consulting for four decades domestically and internationally. $\mathrm{He}$ is a visiting professor in various Latin American universities, including Ecuador. He is Associate Professor of Business, School of Business, M.B.A. Program, Warner University. 


\section{REFERENCES}

1. Acosta, A. (2006). Breve historia económica del Ecuador. Quito, Ecuador: Corporación editor nacional.

2. Arosemena-Arosemena, Guillermo (2007). Las empresas apuntan a fusiones. Expreso de Guayaquil. Abril 30, 14-15.

3. Arosemena-Arosemena, G. (2008). Hacia la superación gerencial. Industrias, Septiembre, 13(20).

4. Bateman, T. \& Snell, S. (2002). Management: Competing in the new era. (5 $5^{\text {th }}$ ed). Boston: McGraw-Hill Irwin.

5. $\quad$ Correa, S. (2008). Benchmarking: en busca de las mejores prácticas. Industrias. Noviembre 13 (11), 36.

6. Hodge, B.J. A., William, \& Gales, Lawrence. (2003). Organization theory: A strategic approach. (6 $6^{\text {th }}$ ed.). Upper Saddle River, New Jersey: Prentice Hall.

7. Hurtado, O. (2007). El poder político en Ecuador. (17 ed). Quito, Ecuador: Editorial Planeta del Ecuador.

8. Jones, G. \& Jones,. (2007). Contemporary management. ( $2^{\text {nd }}$ Edition). Boston: McGraw-Hill Irwin.

9. Kreitner, R. (2001). Management. (8th ed). Boston: Houghton Mifflin Company.

10. Luna Osorio, L. (2007). Proyección del Ecuador al mundo: 2007-2010. Quito, Ecuador: Pudeleco Editores.

11. Lucio-Paredes, P. (2008). En busca de la constitución perdida. Quito, Ecuador: TRAMA Ediciones.

12. Ospina Peralta, P. (2007). Nuestro Ecuador. Manual de realidad nacional. Quito, Ecuador: Universidad Andina Simón Bolívar.

13. Robins, S. \& Coulter, M. (2005). Management. $\left(8^{\text {th }}\right.$ ed). Upper Saddle River, New Jersey: Prentice Hall.

14. Schein, E., H. (1985). Organizational culture and leadership. San Francisco: Jossey- Bass

15. Schein, E., H. (1988). Process consultation, Vol. 1: Its role in organization development. (2nd ed) Reading, Mass: Addison-Wesley Publishing Company.

16. Theodore, J. (2004). Desarrollo de organizaciones: una apuesta a la eficiencia. Ekos, Junio, 125-130.

17. Theodore, J. (2003). Holistic management. EAN. 47, Enero-Abril 122-136.

18. Theodore, J. (2002). Organization Development: Target Areas and Goals for Planned Change Interventions. The New Zealand Institute of Management, March-April 52-65

19. Theodore, J (1999). The impact of religious, social, and economic forces upon the development of management education in Latin America. Journal of Third World Studies. 16, (2), 133-139.

20. Vásquez, Lola \& Napoleón Santos (2008). Ecuador: Su realidad. Quito, Ecuador. Fundación de investigación y promoción social "José Peralta" 
NOTES 